\title{
THE ELECTROCARDIOGRAM IN CARDIOMYOPATHY
}

\author{
BY \\ R. M. HOLLISTER* AND J. F. GOODWIN \\ From the Department of Medicine, Postgraduate Medical School, Ducane Road, London W.12 \\ Received August 15, 1962
}

Cardiomyopathy has been defined as "a subacute or chronic disorder of heart muscle of unknown or obscure ætiology, often with associated endocardial, and sometimes with pericardial, involvement, but not atherosclerotic in origin". Using this definition a differentiation of chronic cardiomyopathies into three types has been made on clinical grounds (Goodwin et al., 1961).

Obstructive Cardiomyopathy. We have given this term to a group of disorders that are characterized by diffuse obstruction to outflow from the left ventricle below the aortic valve (Goodwin $e t$ al., 1960). We believe the commonest cause to be asymmetrical hypertrophy of the heart mainly involving the ventricular septum (Teare, 1958). In some patients, the major obstruction involves the inflow tract of the left ventricle, or both outflow and inflow tracts of the right ventricle, when there is evidence of obstruction at more than one site. But the commonest presentation is that of left ventricular outflow tract obstruction.

The clinical features are a normal or jerky arterial pulse; an ejection murmur of late onset maximal at the left sternal edge (and often a thrill); and absence of aortic valvular calcification or dilatation of the ascending aorta (Goodwin et al., 1960). Commonly, a family history of heart disease or of sudden death is present, and the condition mimics aortic valvular or sub-valvular stenosis. Obstruction involving the left ventricular or right ventricular inflow tracts may present signs of mitral and tricuspid stenosis respectively, while muscular obstruction to right ventricular outflow simulates pulmonary stenosis.

Congestive Cardiomyopathy. This, the commonest form of cardiomyopathy, is characterized by cardiomegaly, gallop rhythm, and often pan-systolic murmurs due to mitral or tricuspid valvular insufficiency. It frequently simulates ischæmic heart disease.

Constrictive Cardiomyopathy. This, the least common of the three clinical forms of cardiomyopathy, generally shows no remarkable cardiac enlargement, murmurs are trivial or absent, but a third heart sound is common, the jugular venous pressure is raised, and there are steep " $x$ " and " $y$ " descents. The venous pressure may rise in inspiration. This type must be distinguished from constrictive pericarditis.

The object of this paper is to present an analysis of the cardiographic appearances in the three types of cardiomyopathy, and to compare these appearances with those of cardiograms of patients with disorders that clinically resemble the cardiomyopathies.

\section{SubJeCtS AND MeTHODS}

The electrocardiograms of 28 patients with obstructive, 25 patients with congestive, and 9 patients with constrictive cardiomyopathy have been analysed. Of the 28 patients with obstructive cardiomyopathy, 15 were men and 13 women, the average age being 20 years. The underlying pathological condition was considered to be asymmetrical hypertrophy in all except one patient, who, at operation, appeared to have a displaced aortic cusp of the mitral valve, hypertrophy of the outflow tract of the left ventricle, and some

This work was carried out during the tenure of a post-doctoral fellowship from the National Heart Institute, National Institute of Health, U.S. Public Health Service. 
endocardial fibrosis. Of the 25 patients with congestive cardiomyopathy, 15 were men and 10 women, the average age being 51 years. Of the 9 with constrictive cardiomyopathy, 8 were men and 1 was a woman, the average age being 48 years.

The diagnosis of obstructive, congestive, or constrictive cardiomyopathy was made primarily on clinical grounds, and was confirmed in the majority of patients by cardiac catheterization and angiocardiography, by operation, or by necropsy.

The pathological conditions that produced the clinical syndromes studied are listed in Table I.

TABLE I

Pathological basis for Cardiomyopathy in Patients Studied

\begin{tabular}{|c|c|c|c|c|c|c|c|}
\hline \multicolumn{7}{|c|}{ Anatomical diagnosis and associated conditions } & No. of patients \\
\hline $\begin{array}{l}\text { Obstructive cardiomyopathy } \\
\text { Asymmetrical hypertrophy } \\
\text { Abnormal aortic cusp of mitra }\end{array}$ & i valve & & $\ddot{\cdots}$ & $\begin{array}{l}\cdots \\
\cdots\end{array}$ & $\ddot{\cdots}$ & $\ddot{\cdots}$ & $\begin{array}{r}28 \\
27 \\
1\end{array}$ \\
\hline 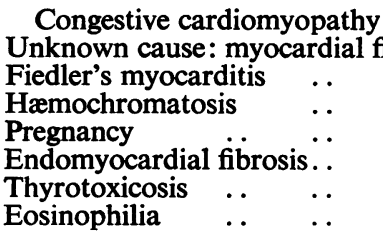 & $\begin{array}{l}\text { ibrosis a } \\
\cdots \\
\cdots \\
\cdots \\
\cdots \\
\cdots\end{array}$ & $\begin{array}{l}\text { and } \\
\ldots \\
\cdots \\
\cdots \\
\cdots \\
\cdots\end{array}$ & $\begin{array}{l}\text { lula } \\
\cdots \\
\ldots \\
\cdots \\
\cdots \\
\cdots\end{array}$ & $\begin{array}{l}\text { afilt } \\
\ldots \\
\ldots \\
\cdots \\
\cdots \\
\cdots\end{array}$ & $\begin{array}{l}\text { on } \\
\cdots \\
\cdots \\
\cdots \\
\cdots \\
\cdots\end{array}$ & $\begin{array}{l}\cdots \\
\cdots \\
\cdots \\
\cdots \\
\cdots\end{array}$ & $\begin{array}{r}25 \\
14 \\
4 \\
2 \\
2 \\
1 \\
1 \\
1\end{array}$ \\
\hline $\begin{array}{l}\text { Constrictive cardiomyopathy } \\
\text { Primary amyloid ... } \\
\text { Polyarteritis nodosa } \\
\text { Leukæmia } \\
\text { Endomyocardial fibrosis.. } \\
\text { Loeffler's "endomyocarditis" } \\
\text { Unknown .. } \quad . .\end{array}$ & $\begin{array}{l}\ldots \\
\cdots \\
\cdots \\
\cdots \\
\cdots\end{array}$ & $\begin{array}{l}\ddot{ } \\
\ddot{*} \\
\ddot{*} \\
\ddot{*}\end{array}$ & $\begin{array}{l}\ddot{ } \\
\cdots \\
\cdots \\
\cdots \\
\cdots\end{array}$ & $\begin{array}{l}\cdots \\
\ldots \\
\ldots \\
\ldots \\
\ldots\end{array}$ & $\begin{array}{l}\ddot{ } \\
\ddot{*} \\
\ddot{ } \\
\cdots\end{array}$ & $\begin{array}{l}\cdots \\
\cdots \\
\cdots \\
\ddot{*} \\
\cdots\end{array}$ & $\begin{array}{l}9 \\
3 \\
1 \\
1 \\
2 \\
1 \\
1\end{array}$ \\
\hline
\end{tabular}

We have attempted to determine whether there is an electrocardiographic pattern characteristic of each of the clinical forms of cardiomyopathy. The cardiographic patterns have also been compared with the cardiograms from patients with other diseases that resemble clinically each of the three types of cardiomyopathy. Thus, obstructive cardiomyopathy (OCM) has been compared with aortic valvular stenosis (AS); congestive cardiomyopathy (CM) has been compared with chronic ischæmic heart disease (IHD) (without massive cardiac infarction); and constrictive cardiomyopathy (CCM) with constrictive pericarditis (CP). The diagnoses of aortic valve stenosis, ischæmic heart disease, or constrictive pericarditis respectively were confirmed by either operation or by necropsy, or by both.

Those features emerging as important in the respective differential diagnoses have been given special attention. Aortic valvular stenosis was selected as the condition with which to compare obstructive cardiomyopathy, because obstruction to left ventricular outflow is the dominant clinical problem in the majority of patients with the latter condition (Bercu et al., 1958; Björk, Jonsson, and Nordenström, 1958; Teare, 1958; Brock, 1959; Morrow and Braunwald, 1959; Brent et al., 1960; Goodwin et al., 1960; Menges, Brandenburg, and Brown, 1961). Also it seemed possible that the pathological physiology of asymmetrical hypertrophy of the ventricular muscle (the condition which we believe usually gives rise to the clinical picture of obstructive cardiomyopathy) differed fundamentally from that of aortic valvular stenosis, and that this difference might be reflected in the electrocardiogram regardless of the chamber affected.

The Sanborn, Cambridge, or Elema-Schönander A.B. Mingograph Cardirex machine with standard paper $(1 \mathrm{mv}=10 \mathrm{~mm}$.) was used throughout. The electrocardiograms were studied with special reference to the following features: $P$ wave axis; $P$ wave height and shape in leads II, III, aVF; $P-R$ interval in lead II, rhythm, $P$ wave axis, magnitude of the $Q R$ and $S$ waves in each of the 14 leads; $S-T$ segment and $T$ wave magnitude and direction in the 14 leads; ventricular conduction; ventricular balance; the corrected $Q-T$ segment; ventricular activation time in præcordial leads V1, V3, V5, and V7; the mean manifest frontal plane QRS and T wave axes (ÂQRS and $\hat{A} T$ ); and the mean manifest frontal plane axis of the ventricular gradient ( $\hat{\mathbf{E}})$. 
The $\mathbf{P}$ wave axis was determined by the method of Carter, Richter, and Greene (1919). The corrected Q-T segment was determined from the observed Q-T segment and the R-R interval by the method of Kissin, Schwarzschild, and Bakst (1948). The magnitude of the $Q, R$, and $S$ waves, the $S-T$ segment changes, the $T$ wave, and the ventricular activation time were determined by careful direct visual inspection with the use of a reading glass.

The shape and size of the $P$ wave were studied and the occurrence of a right and left atrial type of $P$ wave was noted. A right atrial $P$ wave denoting enlargement of that chamber was defined as one of $2.5 \mathrm{~mm}$. or more in height and a left atrial P wave denoting enlargement of the left atrium as one which was broad and bifid. Right ventricular hypertrophy was graded from 1-4 according to the following criteria.

Grade 1. Dominant R in V4R or S in V5.

Grade 2. Dominant $\mathrm{R}$ in $\mathrm{V} 4 \mathrm{R}$ and $\mathrm{V} 1$, or dominant $\mathrm{R}$ in $\mathrm{V} 4 \mathrm{R}$ and $\mathrm{S}$ in $\mathrm{V} 5$, or dominant $\mathrm{R}$ in $\mathrm{V} 4 \mathrm{R}$ and aVR.

Grade 3. Dominant R in V4R, V1, and aVR with dominant $\mathrm{S}$ in V5.

Grade 4. Dominant $R$ in V4R and V1 exceeding $10 \mathrm{~mm}$. with dominant $\mathrm{S}$ in V5 and $\mathrm{R}$ in VR, and $\mathrm{T}$ inversion in V2 or V3 (Goodwin and Abdin, 1959).

The following grading of the left ventricular hypertrophy has been introduced and is based on the work of Sokolow and Lyon (1949 a and b), Myers, Klein, and Stofer (1948), and Myers (1950).

Grade 1. RV5 greater than $20 \mathrm{~mm}$. or RV5 plus SV1, or SV2 greater than $25 \mathrm{~mm}$. or RVL greater than $13 \mathrm{~mm}$.

Grade 2. S-T depression or flat $\mathrm{T}$ waves in left præcordial leads and V1 with voltage changes and left axis deviation.

Grade 3. As for grade 2, but with $\mathrm{T}$ inversion.

Grade 4. Deep T inversion (4-5 mm.) otherwise as for grades 2 and 3.

Combined ventricular hypertrophy was defined as signs of left ventricular hypertrophy with one of the following: right axis deviation or normal axis; dominant RVR and/or RV4R, and RV1; dominant S in V5 (Pagnoni and Goodwin, 1952). Alternatively signs of right ventricular hypertrophy with left axis deviation or a deep S in VR $(15 \mathrm{~mm}$.) were considered evidence of combined hypertrophy.

The ÂQRS and ÂT and E were determined by the method of Ashman, Byer, and Bayley (1943).

\section{RESULTS}

General Electrocardiographic Findings in Cardiomyopathy. Atrial hypertrophy was common to all groups, being noted in 78 per cent of patients with obstructive cardiomyopathy, 52 per cent of those with congestive cardiomyopathy, and 55 per cent of those with constrictive cardiomyopathy. The $P$ wave axis, the $P-R$, and $R-R$ intervals were within normal limits in each of the three groups studied. Atrial fibrillation occurred in 3 per cent of patients with obstructive cardiomyopathy, in 28 per cent of patients with congestive cardiomyopathy, and in 11 per cent of those with constrictive cardiomyopathy. First degree heart block occurred in none of the patients with obstructive cardiomyopathy, in 24 per cent of those with congestive cardiomyopathy, and in 14 per cent of those with constrictive cardiomyopathy (Table II; Fig. 1 and 2).

Lone right ventricular hypertrophy was noted in 4 per cent of patients with obstructive cardiomyopathy, 5 per cent of patients with congestive cardiomyopathy, and 45 per cent of those with constrictive cardiomyopathy. Lone left ventricular hypertrophy was present in 22 per cent of patients with obstructive cardiomyopathy, but in none of those with either congestive cardiomyopathy or constrictive cardiomyopathy. Combined ventricular hypertrophy was diagnosed in 48 per cent of patients with obstructive cardiomyopathy, 32 per cent of those with congestive cardiomyopathy, and in 12 per cent of those with constrictive cardiomyopathy (Fig. 2). A normal ventricular balance was noted in 26 per cent of patients with obstructive cardiomyopathy, 63 per cent of those with congestive cardiomyopathy and 43 per cent of those with constrictive cardiomyopathy. The average height of the $\mathrm{R}$ wave in lead I was approximately twice as great in patients with obstructive cardiomyopathy as in those with congestive cardiomyopathy and approximately twice as great in congestive cardiomyopathy as in constrictive cardiomyopathy. The voltage of the $R$ wave was greatest in patients with obstructive cardiomyopathy, less in those with congestive cardiomyopathy, and least in those with constrictive cardiomyopathy in leads I, V3, V5, and V7 (Table II, Fig. 3). 
.

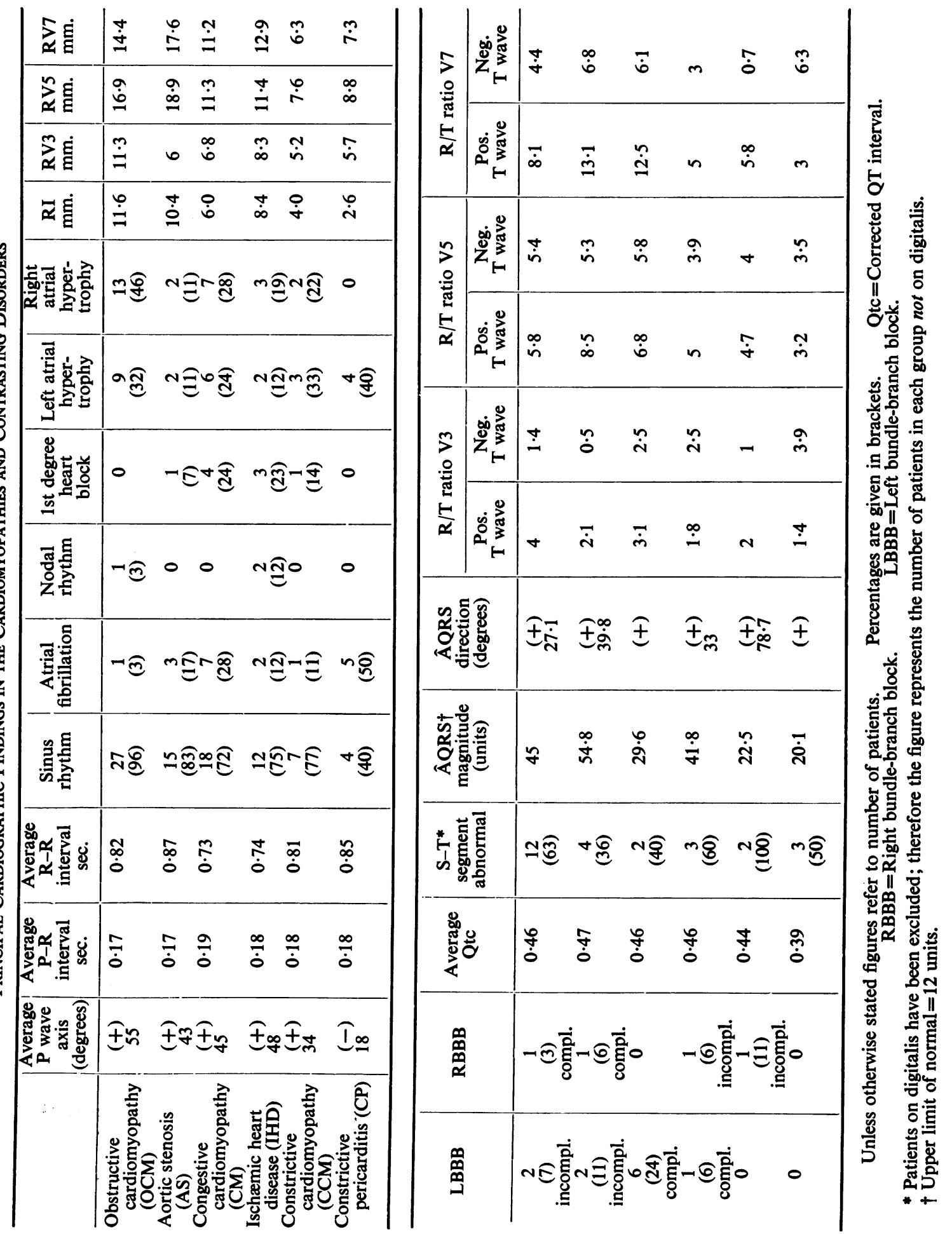




\section{Atrial Fibrillation Heart Block \& Qtc in Cardiomyopathy}

FIG. 1.-Atrial fibrillation, heart block, and corrected Qt interval (QTc) in the three types of cardiomyopathy.

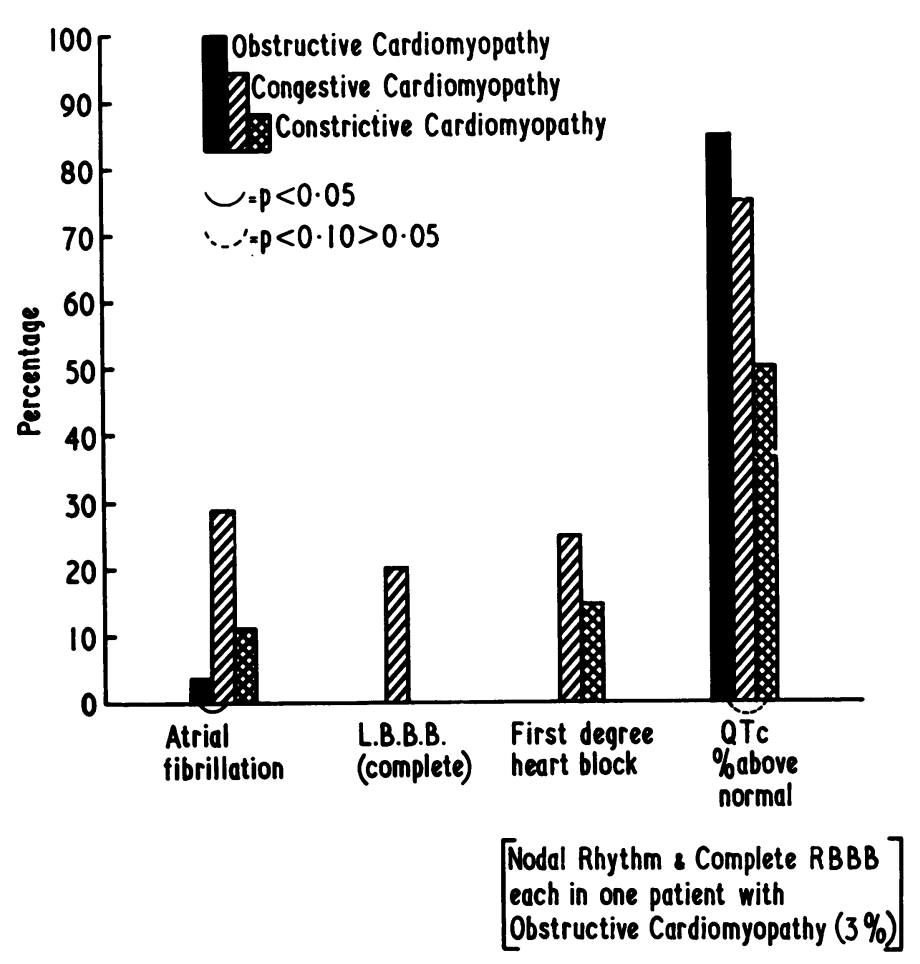

Obstructive Cardiomyopathy

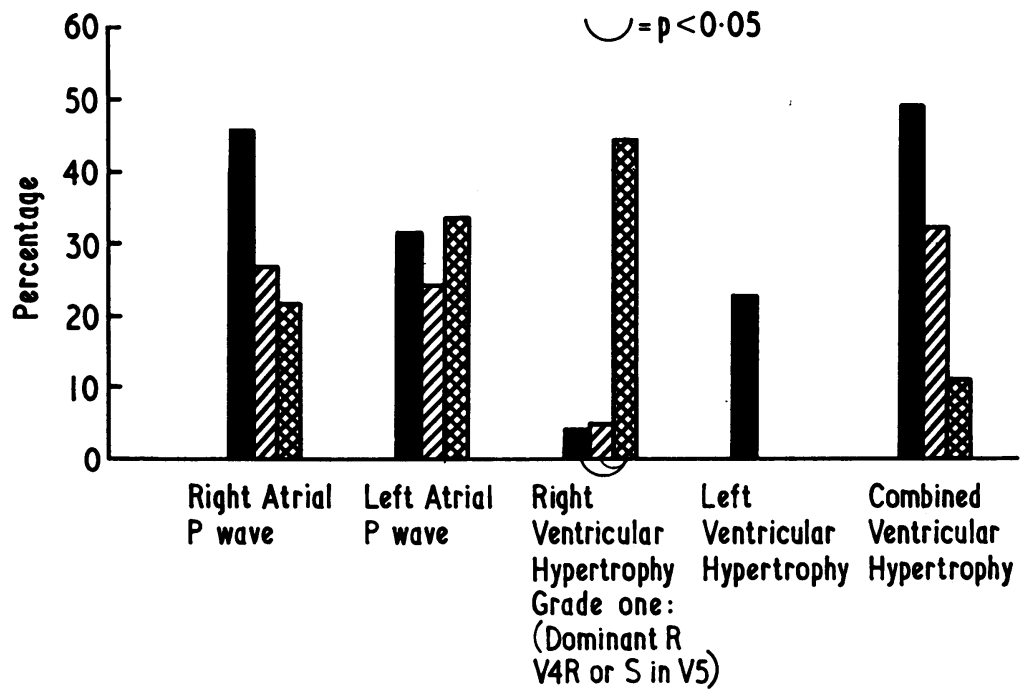

Fig. 2.-P wave changes and ventricular balance in the three types of cardiomyopathy. 
Obstructive Cardiomyopathy

Congestive Cardiomyopathy

Constrictive Cardiomyopathy

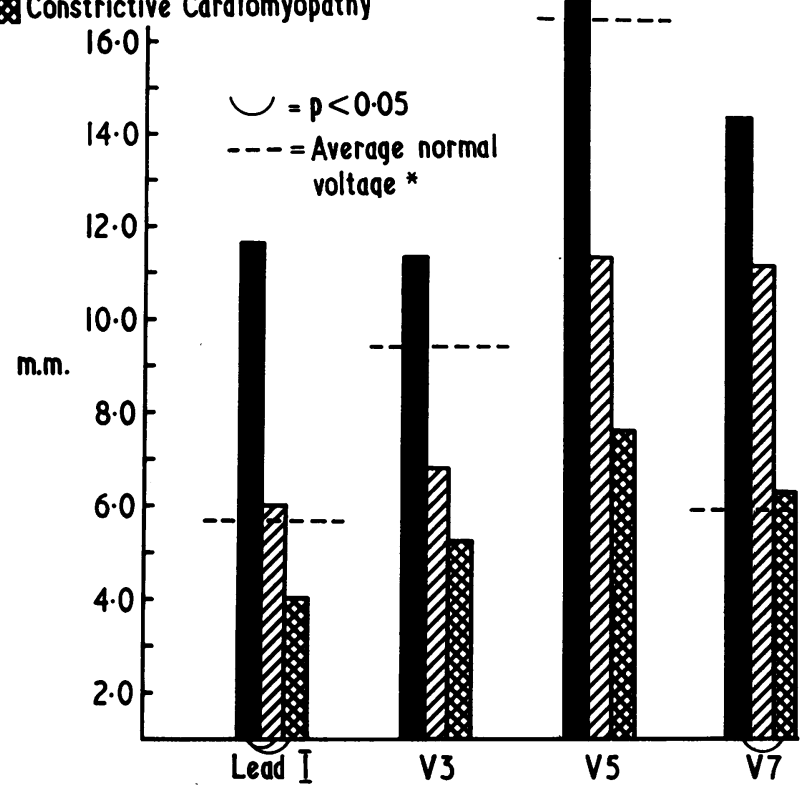

Fig. 3.-Voltage of $\mathbf{R}$ wave (vertical ordinate) in leads $1, \mathrm{~V} 3, \mathrm{~V} 5$, and V7 in the three types of cardiomyopathy.

Obstructive Cardiomyopathy

(28 patients)

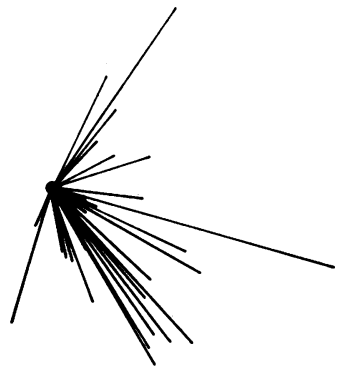

Average : $+27^{\circ}$

45 Ashman units

Mean Manifest Frontal

Plane Axis of QRS

(A QRS) $1 / 2 \mathrm{~s}$
Congestive Cordiomyopathy

(25 patients)

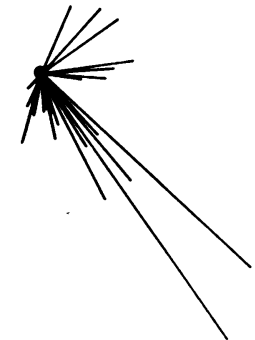

Average : $+50^{\circ}$

29.6 Ashman units

Mean Manifest Frontal

Plane Axis of QRS

(A QRS) $1 / 2 \mathrm{~s}$
Constrictive Cardiomyopathy

(9 patients)

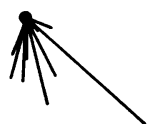

Average : $+78.7^{\circ}$

22.5 Ashman units

Mean Manifest Frontal

Plane Axis of QRS

(A QRS) $1 / 2 s$

Fig. 4.-Mean frontal plane axis of QRS (ÂQRS) in the three types of cardiomyopathy. 
Complete right bundle-branch block was noted in 3 per cent of patients with obstructive cardiomyopathy, none of those with congestive cardiomyopathy, and in 11 per cent of those with constrictive cardiomyopathy. Complete left bundle-branch block was noted in none of the patients with obstructive cardiomyopathy, in 24 per cent of those with congestive cardiomyopathy, and in none of those with constrictive cardiomyopathy (Table II, Fig. 1).

The magnitude of AQRS and $E$ was greater than normal, and the direction normal in each of the three groups (Table II, Fig. 4). The corrected Q-T interval (QTc) was abnormally prolonged in all three groups, but least so in patients with constrictive cardiomyopathy (Table II).

There was S-T elevation or depression of 1-2 mm. (excluding patients on digitalis) in approximately half the patients with obstructive cardiomyopathy and congestive cardiomyopathy, and in all of the constrictive cardiomyopathy group (Table II), but the numbers are too small to be significant.

Left ventricular activity as measured by the sum of the $R$ wave in V5 and the $S$ wave in V1 (RV5 and SV1) averaged $36.9 \mathrm{~mm}$. and right ventricular activity measured by the sum of the $R$ in $\mathrm{V} 1$ and the S in V5 (RV1+SV5) averaged $9 \mathrm{~mm}$. with a range of 0-25 mm. in obstructive cardiomyopathy. Left ventricular activity in patients with congestive cardiomyopathy averaged $22.5 \mathrm{~mm}$. with a range of $4.5-71 \mathrm{~mm}$., and right ventricular activity averaged 5.6 with a range of $1-12 \mathrm{~mm}$. Patients with constrictive cardiomyopathy showed an average left ventricular activity of 16.5 $\mathrm{mm}$. (range 6-37 mm.), and an average right ventricular activity of $6 \cdot 1 \mathrm{~mm}$. (range $0.5-13 \mathrm{~mm}$.) (Table II). This finding is in accord with the observation noted above that the highest voltages occurred in obstructive cardiomyopathy, less in congestive cardiomyopathy, and the least in constrictive cardiomyopathy. Average right ventricular activity was lower in all three groups than average left ventricular activity.

TABLE III

\begin{tabular}{|c|c|c|c|c|c|c|c|c|c|}
\hline & & & & & \multicolumn{4}{|c|}{ Ventricular activity } & \\
\hline & & & & & \multicolumn{2}{|c|}{ Left } & \multicolumn{2}{|c|}{ Right } & \\
\hline & & & & & \multicolumn{2}{|c|}{$\begin{array}{c}\text { Voltage } \\
\text { RV5+SV1 }\end{array}$} & \multicolumn{2}{|c|}{$\begin{array}{c}\text { Voltage } \\
\text { RV1+SV5 }\end{array}$} & $\begin{array}{c}\text { Voltage } \\
\text { RV5+SV1 }\end{array}$ \\
\hline & & & & & $\begin{array}{c}\text { Average } \\
(\mathrm{mm} .)\end{array}$ & $\begin{array}{l}\text { Range } \\
(\mathrm{mm} .)\end{array}$ & $\begin{array}{c}\text { Average } \\
(\mathrm{mm} .)\end{array}$ & $\begin{array}{l}\text { Range } \\
\text { (mm.) }\end{array}$ & Average \\
\hline $\begin{array}{l}\text { Obstructive cardiomyopathy } \\
\text { Aortic stenosis ... } \\
\text { Congestive cardiomyopathy } \\
\text { Ischæmic heart disease . . } \\
\text { Constrictive cardiomyopathy } \\
\text { Constrictive pericarditis ... }\end{array}$ & $\begin{array}{l}. \\
\because \\
\because \\
\because \\
\ldots\end{array}$ & $\begin{array}{l}. \\
\cdots \\
\cdots \\
\cdots \\
\cdots\end{array}$ & $\begin{array}{l}. \\
\cdots \\
\cdots \\
\cdots \\
\cdots\end{array}$ & $\begin{array}{l}. . \\
\cdots \\
\cdots \\
\cdots \\
\cdots\end{array}$ & $\begin{array}{l}36 \cdot 9 \\
40 \cdot 9 \\
22 \cdot 5 \\
24 \cdot 5 \\
16 \cdot 5 \\
14 \cdot 5\end{array}$ & $\begin{array}{r}10-44 \\
18-68 \\
4 \cdot 5-71 \\
3-40 \\
6-37 \\
5-25\end{array}$ & $\begin{array}{r}9 \cdot 0 \\
4 \cdot 6 \\
5 \cdot 6 \\
11 \cdot 3 \\
6 \cdot 1 \\
4 \cdot 2\end{array}$ & $\begin{array}{l}0-25 \\
0-16 \\
1-12 \\
2 \cdot 5-30 \\
0 \cdot 5-13 \\
0 \cdot 2-12 \cdot 5\end{array}$ & $\begin{array}{r}12 \cdot 6 \\
24.0 \\
6 \cdot 8 \\
3 \cdot 8 \\
10 \cdot 1 \\
13 \cdot 3\end{array}$ \\
\hline
\end{tabular}

An $R$ wave of $20 \mathrm{~mm}$. or more with an inverted T wave in leads V5-7 was noted in 25 per cent of patients with obstructive cardiomyopathy, 4 per cent of those with congestive cardiomyopathy, but in none of those with constrictive cardiomyopathy. A dominant $R$ wave was present in V4 in 16 per cent of patients with congestive cardiomyopathy, but in only 3 per cent of those with obstructive cardiomyopathy, and was not found in constrictive cardiomyopathy.

Most of the patients with each of the three types of cardiomyopathy showed an rS pattern in leads V4R, V1, and V3, and an Rs pattern in V5. Of patients with constrictive cardiomyopathy 30 per cent had an $\mathrm{rS}$ pattern in V5. In V7 a monophasic $R$ was most frequently found in patients with obstructive cardiomyopathy and congestive cardiomyopathy, whereas among those with constrictive cardiomyopathy an Rs or rS pattern was characteristic. 
The $\mathrm{R} / \mathrm{S}$ ratio was calculated in each of the types of cardiomyopathy in leads V4R, V1, V3, V5, and V7. In lead V4R the $R / S$ ratio averaged 0.48 in obstructive cardiomyopathy, 0.22 in congestive cardiomyopathy, and 0.23 in constrictive cardiomyopathy (Table IV).

Thus, the highest ratio in V4R was in obstructive cardiomyopathy. This was also true in V1, where the average values were $0.38,0.25$, and 0.16 respectively. In V3, however, the patients with constrictive cardiomyopathy showed the highest average $\mathrm{R} / \mathrm{S}$ ratio which was $1 \cdot 1$ : those patients

TABLE IV

R/S RATIOS IN THE CARdiomyopathies

\begin{tabular}{|c|c|c|c|c|c|c|c|c|c|}
\hline & \multicolumn{3}{|c|}{ Obstructive cardiomyopathy } & \multicolumn{3}{|c|}{ Congestive cardiomyopathy } & \multicolumn{3}{|c|}{ Constrictive cardiomyopathy } \\
\hline Lead & Mean & Range & $\begin{array}{c}\text { No. and } \\
\text { per cent }>1\end{array}$ & Mean & Range & $\begin{array}{c}\text { No. and } \\
\text { per cent }>1\end{array}$ & Mean & Range & $\begin{array}{c}\text { No. and } \\
\text { per cent }>1\end{array}$ \\
\hline V4R & 0.48 & $0 \cdot 04-1 \cdot 7$ & $\begin{array}{c}3 \\
(16)\end{array}$ & 0.22 & $0.02-0.5$ & 0 & $0 \cdot 23$ & $0.1-0.5$ & $\mathbf{0}$ \\
\hline V1 & $0 \cdot 38$ & $0 \cdot 01-1 \cdot 4$ & 2 & 0.25 & $0.03-1$ & 0 & $0 \cdot 16$ & $0.05-0.5$ & $\mathbf{0}$ \\
\hline V3 & 0.87 & $0.05-4 \cdot 8$ & $\begin{array}{l}17 \\
7 \\
\text { (26) }\end{array}$ & 0.82 & $0.01-10$ & 3 & $1 \cdot 1$ & $0 \cdot 04-7 \cdot 0$ & $\underset{(22)}{2}$ \\
\hline V5 & $2 \cdot 7$ & $0 \cdot 1-9$ & $\underset{(24)}{4}$ & $2 \cdot 7$ & $0.02-7 \cdot 7$ & $\begin{array}{c}5 \\
(26)\end{array}$ & $3 \cdot 8$ & $0 \cdot 2-19$ & 3 \\
\hline v7 & $6 \cdot 1$ & $0.6-27$ & $\begin{array}{l}1 \\
(10)\end{array}$ & $5 \cdot 1$ & $0 \cdot 70-17$ & $\begin{array}{c}1 \\
1 \\
(17)\end{array}$ & $7 \cdot 8^{*}$ & $0 \cdot 2-32$ & $\begin{array}{c}43) \\
2 \\
(30)\end{array}$ \\
\hline
\end{tabular}

Pecentages are given in brackets.

* If one patient with an $S$ wave of $0.5 \mathrm{~mm}$. is omitted this becomes 3.7 .

with obstructive cardiomyopathy and congestive cardiomyopathy had approximately the same ratios, 0.87 and 0.82 respectively. In $\mathrm{V} 5$ and $\mathrm{V} 7$, the constrictive cardiomyopathy group again showed the highest average values, 3.8 and 7.8 respectively, whereas the values for obstructive cardiomyopathy and congestive cardiomyopathy were smaller in these two leads (Table IV). The high $\mathrm{R} / \mathrm{S}$ ratio in V5 and V7 in the constrictive cardiomyopathy groups was due to the presence in this group of patients with the smallest $\mathrm{S}$ waves.

$T$ Wave Changes. The majority of patients with obstructive cardiomyopathy and congestive cardiomyopathy showed upright $\mathrm{T}$ waves in V4R, whereas 50 per cent of those with constrictive cardiomyopathy were found to have inverted $T$ waves in this lead. In V1, V3, V5, and V7, the majority of patients showed upright $\mathrm{T}$ waves. The number of patients with $\mathrm{T}$ wave inversion in V7 was higher in obstructive cardiomyopathy $(40 \%)$ than in both congestive cardiomyopathy $(25 \%)$ and constrictive cardiomyopathy $(22 \%)$.

$T$ wave voltage followed the same general pattern as $R$ wave voltage. In leads V4R, V1, V3, V5, and V7, T wave voltage was greatest in obstructive cardiomyopathy, less in congestive cardiomyopathy, and least in constrictive cardiomyopathy. This relation obtained in patients with upright or inverted $\mathrm{T}$ waves.

Electrocardiographic Characteristics of Individual Cardiomyopathies. The electrocardiogram in patients with obstructive cardiomyopathy characteristically showed normal $\mathbf{R}-\mathbf{R}$ and $\mathbf{P}-\mathbf{R}$ intervals, a normal $P$ wave axis, and sinus rhythm. Right atrial hypertrophy was a frequent finding $(46 \%)$ whereas atrial fibrillation and first degree heart block were rarely encountered (Fig. 5 and 6).

48 per cent of patients showed combined ventricular hypertrophy, and 25 per cent showed a tall $\mathbf{R}$ wave with inverted $\mathbf{T}$ wave in the left præcordial leads. None of the patients studied showed complete left bundle-branch block, and only one showed complete right bundle-branch block. The average amplitudes of the $R$ waves in standard lead I and præcordial leads, V3, V5, and V7 were greater than normal (Ashman and Hull, 1941; Leatham, 1950), and exceeded in each of these leads the average voltage recorded among the patients with congestive cardiomyopathy and con- 


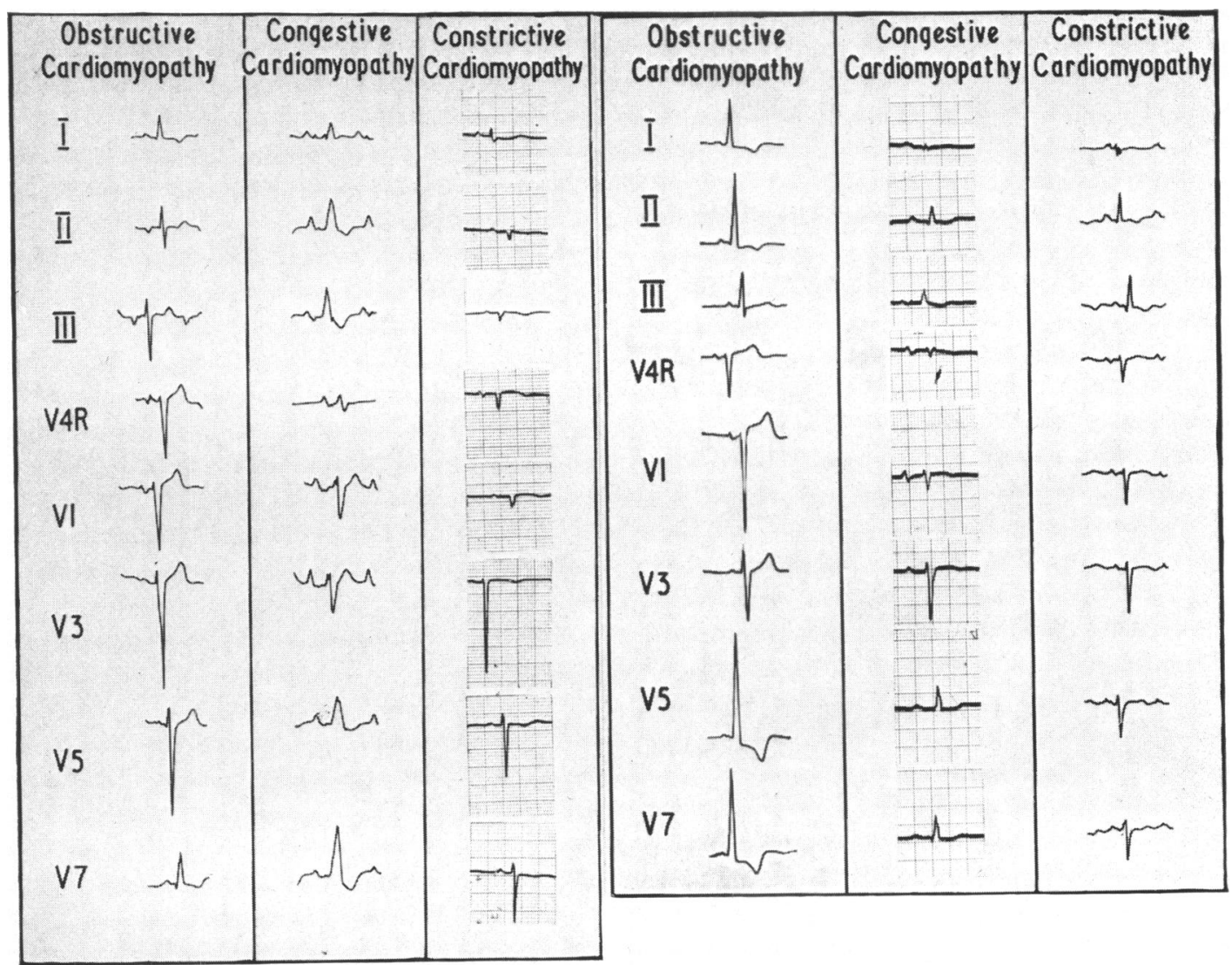

FIG. 5.-Selected electrocardiographic leads in obstructive, congestive, and constrictive cardiomyopathy respectively. In the obstructive graph, left axis deviation, deep $\mathrm{S}$ in V5, and inversion of the $\mathrm{T}$ wave in $\mathrm{V} 7$ are present, indicating biventricular hypertrophy. The congestive graph shows left bundlebranch block. The constrictive graph shows low voltage limb leads, deep $\mathbf{S}$ waves, and flat or slightly inverted $\mathbf{T}$ waves in præcordial leads.

FIG. 6.-Further selected electrocardiographic leads in obstructive, congestive, and constrictive cardiomyopathy respectively. The obstructive graph shows normal cardiac axis, and tall $\mathbf{R}$ waves and inverted $T$ waves in left præcordial leads, indicating grade 4 left ventricular hypertrophy.

The congestive graph shows low voltage and flat $T$ waves with normal ventricular balance.

The constrictive graph shows low voltage, deep $\mathbf{S}$ wave in V5, and 7, and biphasic T waves.

strictive cardiomyopathy. The corrected Q-T interval (QTc) was characteristically prolonged, often to a considerable degree. There was typically an $\mathrm{rS}$ pattern in V4R, V1, and V3, an Rs pattern in V5, and a monophasic $R$ wave in V7. The $R / S$ ratio rose gradually from 0.48 in V4R to $6 \cdot 1$ in V7, and the average values were generally within the same limits for each of the three types of cardiomyopathy.

T wave amplitude was greater among those patients with obstructive cardiomyopathy than among those with either congestive cardiomyopathy or constrictive cardiomyopathy. $\mathrm{T}$ wave inversion occurred most frequently in the left ventricular leads $(40 \%$ in V7) and $\mathrm{S}-\mathrm{T}$ segment changes were noted in more than half the patients when those on digitalis had been excluded.

The most frequent findings among patients with congestive cardiomyopathy were normal sinus rhythm, normal $\mathrm{P}-\mathrm{R}$ and $\mathrm{R}-\mathrm{R}$ intervals, and a normal $\mathrm{P}$ wave axis. Atrial hypertrophy and atrial fibrillation occurred in approximately one-fourth of the patients studied in this group. First-degree heart block was noted in 24 per cent. 
The ventricular balance was usually normal. The average $\mathbf{R}$ wave amplitude exceeded the normal in leads I and V7, and fell within normal limits in leads V1, V3, and V5 (Ashman and Hull, 1941; Leatham, 1950). These values were less than those recorded for patients with obstructive cardiomyopathy and greater than those noted in patients with constrictive cardiomyopathy. Complete left bundle-branch block was noted in approximately one-fourth of the patients studied. The average corrected Q-T interval (QTc) was prolonged and fell between the greater average figure for patients with obstructive cardiomyopathy and the smaller average figure for patients with constrictive cardiomyopathy.

Typically there was an rS pattern in leads V4R, V1, and V3, an Rs pattern in lead V5, and a monophasic $\mathbf{R}$ wave in lead V7.

The average $\mathrm{R} / \mathrm{S}$ ratio increased steadily from $0 \cdot 22$ in $\mathrm{V} 4 \mathrm{R}$ to $5 \cdot 1 \mathrm{in} \mathrm{V7}$, and did not appear to vary significantly in any of the five præcordial leads studied from the corresponding figures for patients with obstructive cardiomyopathy. The $T$ wave was characteristically upright in leads V4R, V1, V3, V5, and V7. T wave inversion occurred in approximately one-fourth of the patients in leads $\mathrm{V} 4 \mathrm{R}, \mathrm{V} 1, \mathrm{~V} 5$, and $\mathrm{V} 7$. In $\mathrm{V} 3, \mathrm{~T}$ wave inversion was noted in 13 per cent. In 40 per cent of patients minor (1-2 mm.) S-T segment changes occurred in the absence of digitalis.

The findings were essentially non-specific, although the incidence of bundle-branch block was noteworthy as compared with the other forms of cardiomyopathy.

Characteristically the electrocardiogram in the group of patients with constrictive cardiomyopathy showed normal sinus rhythm, normal $\mathrm{R}-\mathrm{R}$ and $\mathrm{P}-\mathrm{R}$ intervals, and normal $\mathrm{P}$ wave axis. Left atrial hypertrophy occurred in one-third of the patients, and atrial fibrillation and first degree heart block were each noted in one patient.

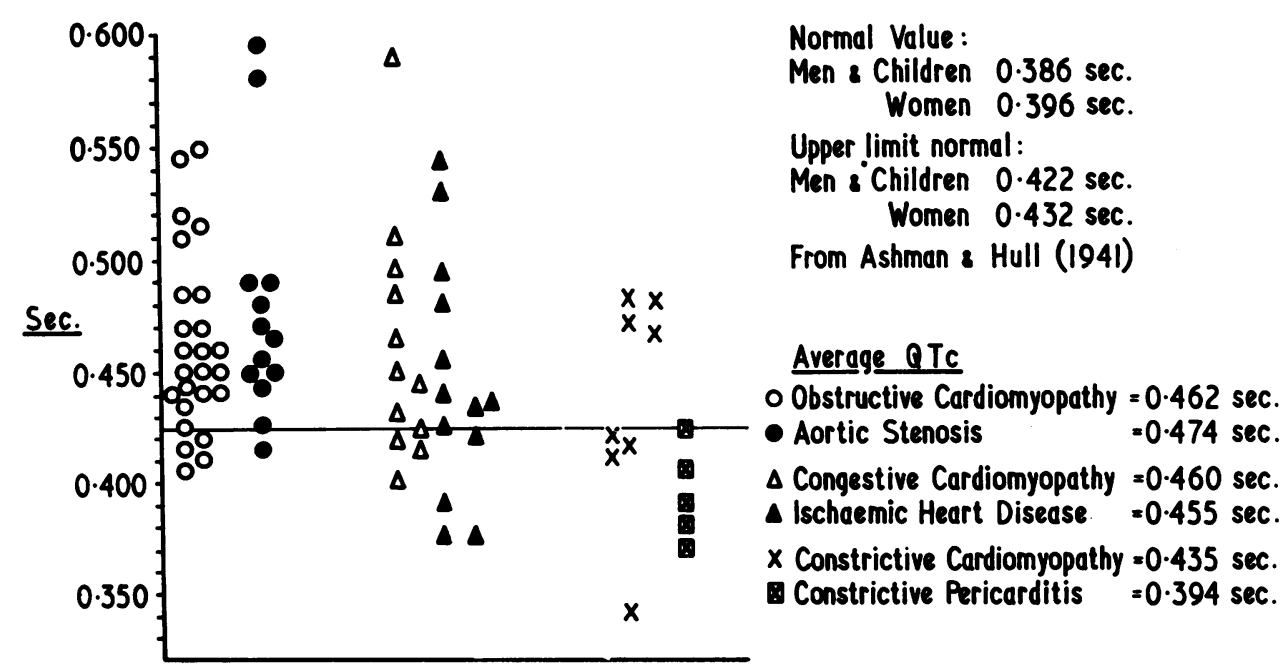

FIG. 7.-QTc in the three types of cardiomyopathy and in aortic stenosis, ischæmic heart disease, and constrictive pericarditis. In the obstructive and constrictive groups and in aortic stenosis and ischæmic heart disease the QTc is usually prolonged, but in half the constrictive group it is short and in constrictive pericarditis it is short in 4 of 5 patients.

Approximately half of the cardiograms showed grade 1 right ventricular hypertrophy, and the majority of the remainder showed a normal ventricular balance. The average $R$ wave amplitude in standard lead I and præcordial leads V3, V5, and V7 was the smallest of the three groups of cardiomyopathy, and was below normal in each lead except V7. Complete bundle-branch block was not noted in this group.

The average corrected Q-T interval (QTc) was above normal, but was the lowest figure of the three groups (Fig. 7). A tall $R$ wave with inverted $T$ waves over the left præcordium was not noted 
among this group. An rS pattern was typically present in leads V4R, V1, and V3; and Rs or rS pattern in V5 and V7. The average $R / S$ ratio varied from 0.23 in lead V4R to $7 \cdot 8$ in lead V7. If one patient with an $S$ wave of $0.5 \mathrm{~mm}$. is omitted, the average $\mathrm{R} / \mathrm{S}$ ratio in $\mathrm{V} 7$ for this group was 3.7 , the smallest in the three types of cardiomyopathy. This figure more accurately reflected the prevalence of an $\mathrm{rS}$ pattern in $\mathrm{V} 7$ than the figure of $7 \cdot 8$.

The $T$ wave was inverted in 50 per cent in lead V4R and was typically upright in leads V1, V3, V5, and V7. It was inverted in approximately one-fourth of the patients in leads V1, V5, and V7 and in 11 per cent in lead V3. There were minor $(1-2 \mathrm{~mm}$.) S-T segment changes in both of the tracings of patients with constrictive cardiomyopathy who were not on digitalis.

TABLE V

T Wave Changes in Cardiomyopathies and Contrasting Disorders

\begin{tabular}{|c|c|c|c|c|c|c|c|c|c|c|c|c|c|c|c|}
\hline & & & & \multicolumn{6}{|c|}{ Lead V4R } & \multicolumn{6}{|c|}{ Lead V1 } \\
\hline \multicolumn{4}{|c|}{ T wave } & OCM & AS & CM & IHD & $\mathbf{C C M}$ & $\mathrm{CP}$ & OCM & AS & CM & IHD & $\mathrm{CCM}$ & $\mathrm{CP}$ \\
\hline $\begin{array}{l}\text { Upright } \\
\text { Inverted } \\
\text { Biphasic o }\end{array}$ & $\begin{array}{l}\cdots \\
\text { r flat }\end{array}$ & $\begin{array}{l}\cdots \\
\cdots\end{array}$ & $\cdots$ & $\begin{array}{c}21 \\
(75) \\
6 \\
(21) \\
1\end{array}$ & $\begin{array}{c}10 \\
(55) \\
3 \\
(16) \\
5\end{array}$ & $\begin{array}{c}6 \\
(54) \\
3 \\
(27) \\
2\end{array}$ & $\begin{array}{c}10 \\
(83) \\
1 \\
(8) \\
1\end{array}$ & $\begin{array}{c}2 \\
(25) \\
4 \\
(50) \\
1\end{array}$ & $\begin{array}{c}4 \\
(57) \\
2 \\
(28) \\
1\end{array}$ & $\begin{array}{c}19 \\
(73) \\
5 \\
(19) \\
2 \\
(7)\end{array}$ & $\begin{array}{c}11 \\
(69) \\
2 \\
(12) \\
3 \\
(18)\end{array}$ & $\begin{array}{c}11 \\
(57) \\
5 \\
(26) \\
3 \\
(16)\end{array}$ & $\begin{array}{c}7 \\
(87) \\
1 \\
(12) \\
0\end{array}$ & $\begin{array}{c}5 \\
(71) \\
2 \\
(28) \\
0\end{array}$ & $\begin{array}{c}3 \\
(43) \\
2 \\
(43) \\
1 \\
(14)\end{array}$ \\
\hline \multicolumn{2}{|c|}{ Biphasic or flat } & & & \multicolumn{6}{|c|}{ Lead V3 } & \multicolumn{6}{|c|}{ Lead V5 } \\
\hline $\begin{array}{l}\text { Upright } \\
\text { Inverted } \\
\text { Biphasic o }\end{array}$ & $\begin{array}{l}\cdots \\
\text { r flat }\end{array}$ & $\begin{array}{l}\cdots \\
\cdots\end{array}$ & $\cdots$ & $\begin{array}{c}21 \\
(75) \\
4 \\
(14) \\
3 \\
(11)\end{array}$ & $\begin{array}{c}14 \\
(87) \\
1 \\
(6) \\
2 \\
(12)\end{array}$ & $\begin{array}{c}18 \\
(81) \\
3 \\
(13) \\
1 \\
(4)\end{array}$ & $\begin{array}{c}12 \\
(80) \\
2 \\
(13) \\
1 \\
(6)\end{array}$ & $\begin{array}{c}7 \\
(78) \\
1 \\
(11) \\
1 \\
(11)\end{array}$ & $\begin{array}{c}3 \\
(33) \\
5 \\
(55) \\
1 \\
(11)\end{array}$ & $\begin{array}{c}14 \\
(56) \\
9 \\
(36) \\
2 \\
(8)\end{array}$ & $\begin{array}{c}8 \\
(44) \\
9 \\
(50) \\
1 \\
(5)\end{array}$ & $\begin{array}{c}12 \\
(52) \\
7 \\
(30) \\
4 \\
(16)\end{array}$ & $\begin{array}{c}11 \\
(78) \\
3 \\
(21) \\
0\end{array}$ & $\begin{array}{c}6 \\
(67) \\
2 \\
(22) \\
1 \\
(11)\end{array}$ & $\begin{array}{c}2 \\
(22) \\
5 \\
(55) \\
2 \\
(22)\end{array}$ \\
\hline \multicolumn{2}{|c|}{ Biphasic or flat } & & & \multicolumn{6}{|c|}{ Lead V7 } & \multirow{2}{*}{\multicolumn{6}{|c|}{$\begin{array}{l}\text { Figures refer to numbers of patients } \\
\text { Percentages are in brackets } \\
\text { OCM=Obstructive cardiomyopathy } \\
\text { AS=Aortic stenosis } \\
\text { CM = Congestive cardiomyopathy } \\
\text { IHD=Ischæmic heart disease } \\
\text { CCM=Constrictive cardiomyopathy } \\
\text { CP = Constrictive pericarditis }\end{array}$}} \\
\hline $\begin{array}{l}\text { Upright } \\
\text { Inverted } \\
\text { Biphasic o }\end{array}$ & $\begin{array}{c}\cdots \\
\text { or flat }\end{array}$ & $\ldots$ & $\ldots$ & $\begin{array}{c}14 \\
(52) \\
11 \\
(40) \\
2 \\
(7)\end{array}$ & $\begin{array}{c}6 \\
(35) \\
10 \\
(59) \\
1 \\
(6)\end{array}$ & $\begin{array}{c}9 \\
(56) \\
4 \\
(25) \\
3 \\
(19)\end{array}$ & $\begin{array}{c}8 \\
(61) \\
4 \\
(31) \\
1 \\
(7)\end{array}$ & $\begin{array}{c}5 \\
(55) \\
2 \\
(22) \\
2 \\
(22)\end{array}$ & $\begin{array}{c}2 \\
(25) \\
5 \\
(62) \\
1 \\
(12)\end{array}$ & & & & & & \\
\hline
\end{tabular}

Comment. Thus, although few diagnostic points emerged from the study of the electrocardiograms, certain differential features of importance were noted. Thus, in comparing the three groups the following points were suggestive of obstructive cardiomyopathy: a high voltage $\mathrm{R}$ wave in standard lead I and the præcordial leads; combined ventricular hypertrophy; prolongation of the corrected Q-T interval; a tall $R$ wave in V5-7 with an inverted T wave; normal sinus rhythm; and absence of heart block.

Suggestive of congestive cardiomyopathy were: normal or low voltage $\mathrm{R}$ waves in standard lead I and præcordial leads, normal ventricular balance, atrial fibrillation, bundle-branch block, and first degree heart block.

Suggestive of constrictive cardiomyopathy were: low voltage $\mathrm{R}$ waves in standard lead $\mathrm{I}$ and præcordial leads, a normal or slight prolonged corrected Q-T interval (QTc), grade 1 right ventricular hypertrophy, an Rs or rS pattern in leads V5 or V7.

\section{Comparison of Cardiomyopathy With Clinically Similar Conditions}

The clinical features of obstructive cardiomyopathy resemble those of aortic valvular obstruction; those of congestive cardiomyopathy are similar to those of chronic ischæmic heart disease without 
massive infarction; and those of constrictive cardiomyopathy resemble those of constrictive pericarditis. For this reason a comparison was made of the electrocardiograms of the three pairs of conditions in an effort to discover features of value in the differential diagnoses.

Obstructive Cardiomyopathy and Aortic Stenosis. The electrocardiograms of the 28 patients with obstructive cardiomyopathy described above were compared with those of 18 patients with surgically proven aortic valvular stenosis studied in the same manner.

In both groups in the majority of patients, or in the single largest number of patients, certain features were noted to be virtually identical. There was sinus rhythm, the $R-R$ and $P-R$ intervals were within normal limits, and the $P$ wave axis was within normal limits. Atrial fibrillation and first-degree heart block occurred infrequently in both groups. The average $R$ wave voltage in standard lead I was approximately the same in both conditions and about twice the normal (Ashman and Hull, 1941; Leatham, 1950) (Table II). The corrected Q-T interval (QTc) was abnormally prolonged and to an approximately equal degree in both obstructive cardiomyopathy and aortic valvular obstruction (Fig. 7). Complete left bundle-branch block was absent in both groups and complete right branch block occurred in one patient in both groups (Table II). Both showed an increased AQRS and E magnitude with normal direction (Sodi-Pallares and Calder, 1956). The $\mathrm{R} / \mathrm{T}$ ratios were similar in leads V5 and V7 (Table II).

There appeared to be significant differences between the two groups in the following features: right and left atrial hypertrophy and combined ventricular hypertrophy were more common in cardiomyopathy than in aortic valvular obstruction, while lone left ventricular hypertrophy was less common (Fig. 8). The average $R$ wave amplitude and the $R / T$ ratio in $V 3$ were almost double

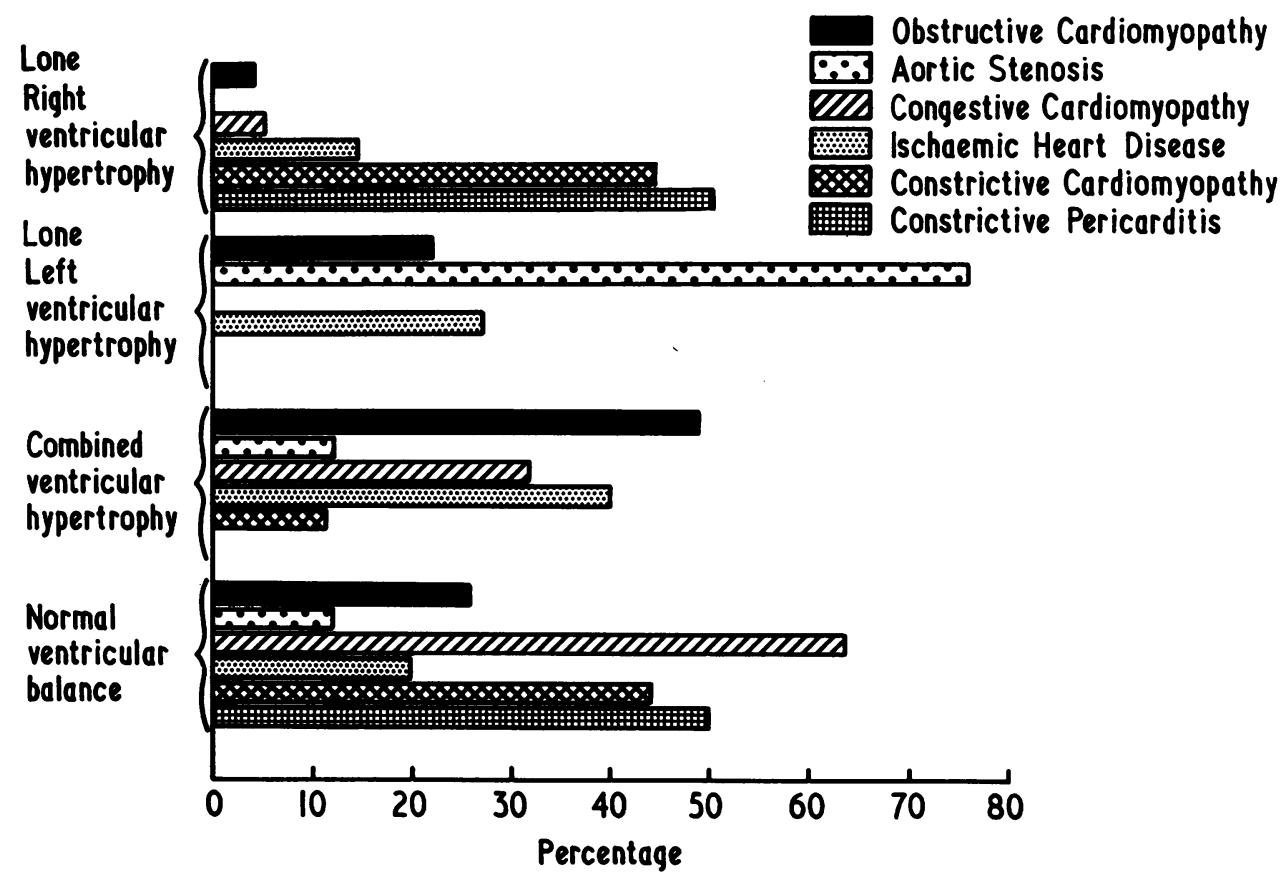

FIG. 8.-Ventricular balance in the three types of cardiomyopathy and in aortic stenosis, ischæmic heart disease, and constrictive pericarditis.

in obstructive cardiomyopathy as in aortic stenosis. The average value of RV5+SV1 was approximately the same for both groups of patients, whereas that of RV1+SV5 was twice as great in obstructive cardiomyopathy as in aortic stenosis. The ratio $\frac{\mathrm{RV} 5+\mathrm{SV} 1}{\mathrm{RV} 1+\mathrm{SV} 5}$ was twice as great in aortic stenosis 
as in obstructive cardiomyopathy (Table II). These data are in accord with the observation that combined ventricular hypertrophy is more frequent in obstructive cardiomyopathy and lone left ventricular hypertrophy is more frequent in aortic stenosis. This may reflect a greater tendency for involvement of the right ventricle in obstructive cardiomyopathy than in aortic stenosis.

$R$ waves of $20 \mathrm{~mm}$. or more with deeply inverted $T$ waves in the left præcordial leads were encountered in 25 per cent of patients with obstructive cardiomyopathy and in 40 per cent of those with aortic stenosis. A dominant $R$ wave in leads V4R, V1, and aVR was infrequently noted in both groups.

An rS complex was the characteristic pattern in leads V4R, V1, and V3 in both groups; an RS complex was usually seen in V4 in obstructive cardiomyopathy and a monophasic $R$ in V5 in aortic stenosis, with a monophasic $R$ in both groups in V7. In leads V4R, V1, and V3, the $T$ wave was usually upright and up to $5 \mathrm{~mm}$. in both groups. In leads V5 and V7 it was upright in approximately half the patients, but more frequently inverted in aortic stenosis than in cardiomyopathy. Leads V3 and V4 were studied separately because of the possibility of a greater incidence of septal involvement among one group of patients than the other. But the $T$ wave was characteristically upright up to $5 \mathrm{~mm}$. in both these leads in both groups of patients when those on digitalis were excluded.

The average $T$ wave amplitude was approximately the same in both groups of patients (with both upright and inverted T waves), in leads V4R, V3, V5, and V7. However, among the patients with inverted $T$ waves the average amplitude of the $T$ waves was three times as great in aortic stenosis as in obstructive cardiomyopathy.

The general cardiographic differences between obstructive cardiomyopathy and aortic stenosis are shown in Table VI. No one cardiogram showed all the differences mentioned, but Fig. 9,

TABLE VI

General Cardiographic Differences Between Obstructive Cardiomyopathy and Aortic Stenosis

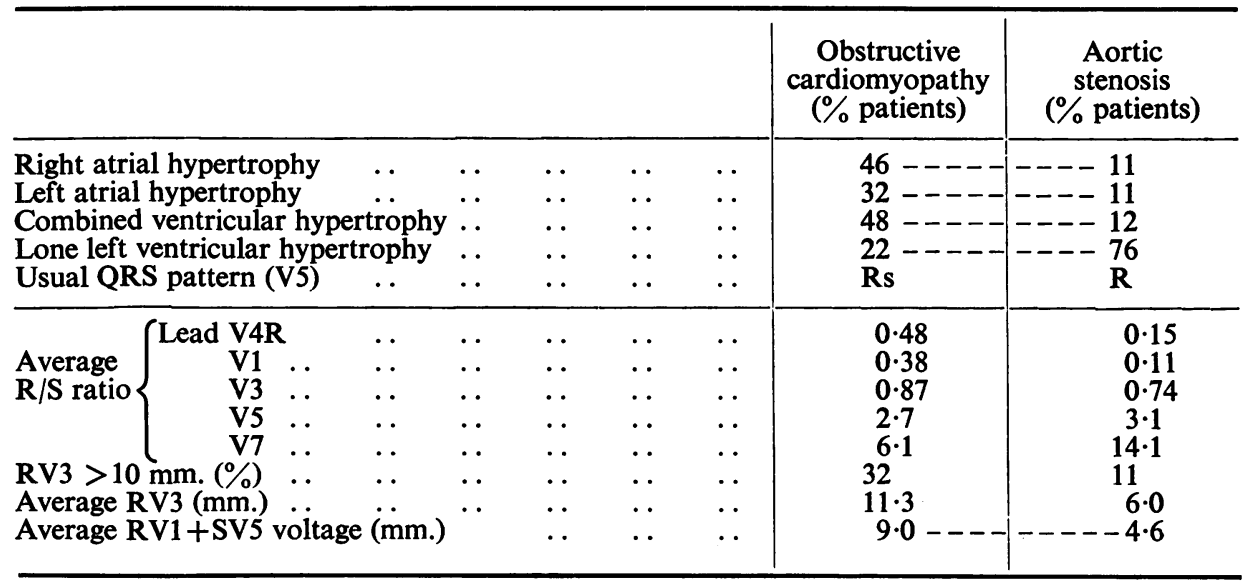

$----=\mathrm{p}<0.05$

which illustrates representative cardiograms of obstructive cardiomyopathy and aortic stenosis, demonstrates certain points. The most important differences were atrial hypertrophy and enlargement of both ventricles in obstructive cardiomyopathy as compared with lone left ventricular hypertrophy in aortic stenosis.

Congestive Cardiomyopathy and Ischomic Heart Disease. The electrocardiograms of patients with congestive cardiomyopathy were compared with those of 16 patients proven to have ischæmic heart disease at necropsy. In the majority of patients, the following features were noted to be virtually identical in congestive cardiomyopathy and in ischæmic heart disease, and within normal 
limits: rhythm, $\mathrm{P}$ wave axis, R-R, and P-R intervals, and first degree heart block $(24 \%$ and $23 \%$ respectively).

Atrial hypertrophy occurred in 52 per cent of patients with congestive cardiomyopathy and 31 per cent of those with ischæmic heart disease. The mean amplitude of the $T$ wave in lead I was slightly above normal in both groups. The amplitude of the R wave in præcordial leads V3, V5, and V7 was approximately equal in both groups. The R/T ratio in V3 and V5 in patients with inverted $\mathrm{T}$ waves was approximately equal in both groups (Table II). The corrected Q-T interval (QTc) was abnormally prolonged to an equal degree in both groups (Fig. 7), and an increased

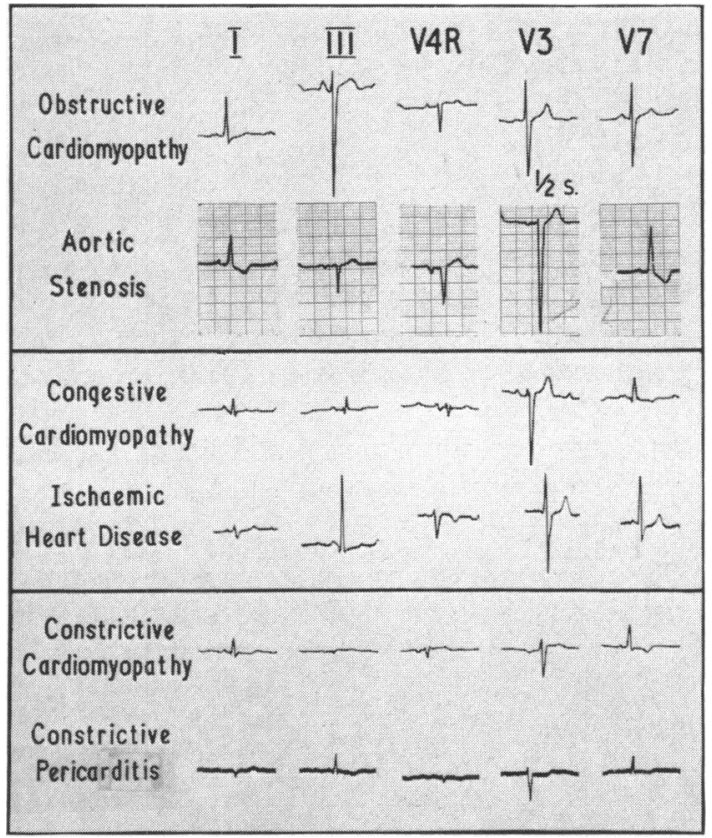

FIG. 9.-Selected leads from patients with the six conditions studied. Note biventricular hypertrophy in obstructive cardiomyopathy as compared with left ventricular hypertrophy in aortic stenosis; low voltage and flat $\mathrm{T}$ wave in $\mathrm{V} 7$ in congestive cardiomyopathy as compared with normal voltage and flat S-T depression in ischæmic heart disease; and low voltage in constrictive pericarditis as compared with constrictive cardiomyopathy.

normal ventricular balance or combined ventricular hypertrophy.

An rS pattern was typically encountered in V4R, V1, and V3 in both groups. In V5 an Rs pattern was noted more frequently in patients with congestive cardiomyopathy and an $\mathrm{rS}$ pattern among those with ischæmic heart disease. In V7 there was a wide variation of QRS patterns in both groups no one of which can be said to be characteristic. In V7 most congestive cardiomyopathy patients showed a monophasic $\mathbf{R}$ wave, whereas in ischæmic heart disease, the largest single group was found to have an $R / S$ ratio between $1 \cdot 6$ and 20 . The average $R / S$ ratio was approximately the same in both groups in V4R; in V1 it was twice as great in ischæmic heart disease as in congestive cardiomyopathy, and in V5 and V7 it was over twice as great in congestive cardiomyopathy as in ischæmic heart disease.

In leads V4R, V1, V3, V5, and V7, the majority of patients in both groups were noted to have upright $\mathrm{T}$ waves between $0-5 \mathrm{~mm}$. in amplitude. The average $\mathrm{T}$ wave amplitude was approximately 
TABLE VII

General Cardiographic Differences Between Congestive Cardiomyopathy and Ischamic Heart DISEASE

\begin{tabular}{|c|c|c|c|c|c|c|}
\hline & & & & & $\begin{array}{c}\text { Congestive } \\
\text { cardiomyopathy } \\
\text { (\% patients) }\end{array}$ & $\begin{array}{l}\text { Ischæmic heart } \\
\text { disease } \\
\text { (\% patients) }\end{array}$ \\
\hline $\begin{array}{l}\text { Atrial fibrillation } \\
\text { Right atrial hypertrophy } \quad \ldots \\
\text { Left atrial hypertrophy } \\
\text { Normal ventricular balance ... } \\
\text { Lone left ventricular hypertrophy } \\
\text { Left bundle-branch block .. }\end{array}$ & $\begin{array}{l}\cdots \\
\cdots \\
\cdots \\
\cdots \\
\cdots\end{array}$ & $\begin{array}{l}. . \\
\therefore \\
. \\
. \\
.\end{array}$ & $\begin{array}{l}\because \\
\because \\
\cdots \\
\cdots \\
\cdots\end{array}$ & $\begin{array}{l}\cdots \\
\cdots \\
\cdots \\
\cdots \\
\cdots\end{array}$ & $\begin{array}{r}28 \\
28 \\
24 \\
63----- \\
0----- \\
24\end{array}$ & $\begin{array}{r}12 \\
19 \\
12 \\
----20 \\
----27 \\
6\end{array}$ \\
\hline $\begin{array}{l}\text { Usual QRS pattern (V5) } \\
\text { Average \{Lead V5 ... } \\
\text { R/S ratio Lead V7 .. } \\
\text { Average RV1+SV5 voltage }\end{array}$ & $\begin{array}{l}\cdots \\
\cdots \\
\cdots\end{array}$ & $\begin{array}{l}. \\
\ldots \\
. .\end{array}$ & $\begin{array}{l}\cdots \\
\cdots \\
\cdots\end{array}$ & $\begin{array}{l}\cdots \\
\cdots \\
\cdots \\
\cdots\end{array}$ & $\begin{array}{l}\text { Rs } \\
2 \cdot 7 \\
5 \cdot 1 \\
5 \cdot 6 \mathrm{~mm} .-\end{array}$ & $\begin{array}{c}\mathrm{rS} \\
1 \cdot 2 \\
2 \cdot 2 \\
---11 \cdot 3 \mathrm{~mm} .\end{array}$ \\
\hline
\end{tabular}

$----=\mathrm{p}<0.05$

the same in leads V4R, V1, V3, and V5 in both groups of patients whether the T wave was upright or inverted. In V7, however, the average $\mathrm{T}$ wave amplitude among patients with ischæmic heart disease was more than twice that of patients with congestive cardiomyopathy whether the $T$ waves were upright or inverted. The general differences are shown in Table VII.

The greater incidence of heart block, arrhythmia, and combined ventricular hypertrophy in congestive cardiomyopathy than in ischæmic heart disease may reflect a more generalized disorder and suggests that the presence of left bundle-branch block of unknown cause should arouse suspicion of cardiomyopathy rather than of ischæmic heart disease.

Constrictive Cardiomyopathy and Constrictive Pericarditis. The electrocardiograms of patients with constrictive cardiomyopathy were similar to those of 10 patients with constrictive pericarditis and within normal limits with respect to the average $\mathbf{R}-\mathbf{R}$ and $\mathbf{P}-\mathbf{R}$ intervals. Complete bundlebranch block was not seen while first-degree heart block occurred in 14 per cent of patients with constrictive cardiomyopathy, and was not noted in constrictive pericarditis. Left atrial hypertrophy was seen with equal frequency in constrictive pericarditis and in constrictive cardiomyopathy, but right atrial hypertrophy did not occur in pericarditis, although it was seen in 22 per cent of cardiomyopathy graphs. $\mathbf{R}$ wave amplitude in standard lead $\mathbf{I}$ was below the mean normal in both groups. In V3 and V5 the amplitude was equal in both groups and approximately one-half the normal amplitude. In V7 it was also approximately equal in the two groups and slightly exceeded the normal amplitude. The magnitude of the AQRS was greater than normal and the direction within normal limits in both groups (Sodi-Pallares and Calder, 1956) (Table II).

Important differences between the two groups are given in Table VIII. The mean $\mathbf{P}$ wave axis was $+34^{\circ}$ in constrictive cardiomyopathy and $-18^{\circ}$ in constrictive pericarditis: atrial fibrillation occurred five times as frequently in constrictive pericarditis as in constrictive cardiomyopathy. The mean corrected Q-T interval (QTc) was greater in constrictive cardiomyopathy and above normal limits (Ashman and Hull, 1941) than in constrictive pericarditis (Table II, Fig. 7). The magnitude of the ventricular gradient was larger than normal in patients with constrictive cardiomyopathy, but within normal limits among patients with constrictive pericarditis (Sodi-Pallares and Calder, 1956) (Table II).

Approximately one-half of the patients in both groups showed grade 1 right ventricular hypertrophy and the other half showed a normal ventricular balance (Fig. 8). The average RV5+SV1, $\mathrm{RV} 1+\mathrm{SV} 5$, and $\frac{\mathrm{RV} 5+\mathrm{SV} 1}{\mathrm{RV} 1+\mathrm{SV} 5}$ voltages were approximately the same in both groups. This is in accord with the observation that a similar type of ventricular balance was noted in the two groups. A 
dominant $\mathrm{R}$ wave in leads V4R and V1 did not occur in constrictive cardiomyopathy but was found in constrictive pericarditis.

The QRS patterns in V4R were of several types in each group without significant differences. In V1 and V3, the characteristic finding was an rS pattern, whereas in V5 an Rs pattern was noted

TABLE VIII

General Cardiographic Differences Between Constrictive Cardiomyopathy and Constrictive PERICARDITIS

\begin{tabular}{|c|c|c|c|c|c|c|c|}
\hline & & & & & & $\begin{array}{c}\text { Constrictive } \\
\text { cardiomyopathy } \\
\text { (\% patients) }\end{array}$ & $\begin{array}{c}\text { Constrictive } \\
\text { pericarditis } \\
(\% \text { patients) }\end{array}$ \\
\hline $\begin{array}{l}\text { Atrial fibrillation } \\
\text { Right atrial hypertrophy }\end{array}$ & $\begin{array}{l}\cdots \\
\cdots\end{array}$ & $\begin{array}{l}\cdots \\
\cdots\end{array}$ & 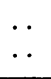 & $\begin{array}{l}\cdots \\
\cdots\end{array}$ & $\begin{array}{l}\cdots \\
\cdots\end{array}$ & $\begin{array}{l}11------ \\
22------\end{array}$ & $\begin{array}{lr}--50 \\
--- & 0\end{array}$ \\
\hline 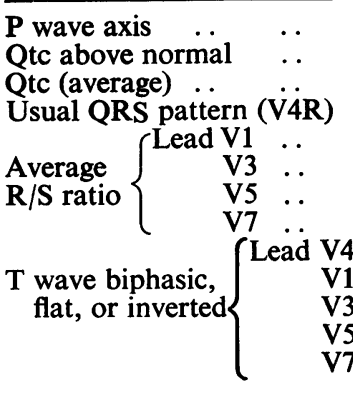 & $\begin{array}{c}\ldots \\
\cdots \\
\ldots \\
\ldots \\
\ldots \\
\ldots \\
\cdots \\
\ldots \\
\ldots \\
\ldots\end{array}$ & $\begin{array}{l}\cdots \\
\cdots \\
\cdots \\
\cdots \\
\cdots \\
\cdots \\
\cdots \\
\cdots \\
\cdots \\
\cdots \\
\cdots\end{array}$ & $\begin{array}{l}\cdots \\
\cdots \\
\cdots \\
\cdots \\
\cdots \\
\cdots \\
\cdots \\
\cdots \\
\cdots \\
\cdots \\
\cdots\end{array}$ & $\begin{array}{l}\cdots \\
\cdots \\
\cdots \\
\cdots \\
\cdots \\
\cdots \\
\cdots \\
\cdots \\
\cdots \\
\cdots \\
\cdots\end{array}$ & $\begin{array}{l}\cdots \\
\cdots \\
\cdots \\
\cdots \\
\cdots \\
\cdots \\
\cdots \\
\cdots \\
\cdots \\
\cdots \\
\cdots\end{array}$ & $\begin{array}{l}+34^{\circ} \\
37 \\
0 \cdot 435 \\
\mathrm{rS} \\
0 \cdot 16 \\
1 \cdot 1 \\
3 \cdot 8 \\
7 \cdot 8 \\
62 \\
28 \\
22 \\
33------ \\
44------\end{array}$ & $\begin{array}{c}-18^{\circ} \\
20 \\
0 \cdot 394 \\
\mathrm{qS} \\
0 \cdot 8 \\
2 \cdot 1 \\
8 \cdot 0 \\
9 \cdot 0 \\
42 \\
57 \\
66 \\
---77 \\
--74\end{array}$ \\
\hline
\end{tabular}

$----=p<0.05$

most frequently. In V7, half the patients with constrictive cardiomyopathy showed an Rs pattern while no one pattern appeared to be characteristic in constrictive pericarditis.

The average $\mathrm{R} / \mathrm{S}$ ratio in $\mathrm{V} 1$ was six times greater in constrictive pericarditis than in constrictive cardiomyopathy, and in V3 it was double. In V5 the figure for constrictive pericarditis was more than twice that of constrictive cardiomyopathy and in V7 the figures were about equal.

Inversion of the $\mathrm{T}$ wave in præcordial leads was more common in constrictive pericarditis than in cardiomyopathy. The average $T$ wave amplitude was approximately the same in each of the five chest leads studied whether the $T$ waves were upright or inverted (Table $V$ ).

\section{Discussion}

Obstructive Cardiomyopathy. The electrocardiogram in this condition may be normal. Two of our patients (with mild clinical signs of the disorder) had normal tracings. Brent et al. (1960) reported three such patients.

Among our group of 28 patients, there were none with complete left bundle-branch block, and only one with complete right bundle-branch pattern. Two patients showed an incomplete left bundlebranch block pattern. Thus, a complete bundle-branch block pattern, either left or right, is a rare finding in obstructive cardiomyopathy and in those patients with obstruction to right ventricular inflow it is a useful differential feature from Ebstein's disease (Hollman et al., 1960).

A review of 38 reported cases of obstructive cardiomyopathy or similar condition (Bercu et al., 1958; Björk et al., 1958; Teare, 1958; Brock, 1959; Morrow and Braunwald, 1959; Brent et al., 1960; Menges et al., 1961) reveals one in which left bundle-branch block was reported (Menges et al., 1961). Right bundle-branch block was noted in 3 patients, which was partial in 2 (Teare, 1958; Brock, 1959). Among the 38 reported, 3 showed atrial fibrillation (Teare, 1958; Brock, 1959), 
but first-degree heart block was not reported. Thus, it appears that, as in our 28 patients, atrial fibrillation and first-degree heart block are rarely encountered in obstructive cardiomyopathy.

As the incidence of first-degree heart block is small in patients with aortic stenosis (Mitchell et al., 1954; Abdin, 1958), it is unlikely that this finding is a useful differential feature. However, Abdin noted atrial fibrillation in one-third of her patients in the series coming to necropsy, and Mitchell reported that 10 per cent of his 131 patients showed this finding. As atrial fibrillation was noted in only 3 per cent of our patients with cardiomyopathy and in 17 of those with aortic stenosis, this difference may be useful in differentiating aortic stenosis from obstructive cardiomyopathy.

It seems logical to suppose that $T$ wave changes in leads near the ventricular septum might be found more frequently in obstructive cardiomyopathy than in aortic stenosis, but in fact such changes occur in both groups in a small proportion of patients.

Thus, no electrocardiographic features have emerged that point toward a unique disorder of myocardial function in obstructive cardiomyopathy. The abnormalities noted differ only in degree and in frequency from those found in patients with aortic valvular stenosis, although the greater tendency for right atrial enlargement in cardiomyopathy is of value in differential diagnosis. The most striking difference between the obstructive and the two other clinical types of cardiomyopathy is in the much higher voltage, the marked QTc prolongation, and the relative absence of disorders of rhythm and conduction in the obstructive type.

Congestive Cardiomyopathy. The high incidence of normal ventricular balance or combined ventricular hypertrophy suggesting generalized muscle involvement is of value in differentiating congestive cardiomyopathy from ischæmic heart disease. The relatively high incidence of atrial fibrillation and complete left bundle-branch block is further evidence of generalized muscle damage in this group and is of value in the differential diagnosis.

Constrictive Cardiomyopathy. Prolongation of the QTc, unimpressive præcordial $\mathrm{T}$ wave inversion, the frequent occurrence of a dominant $S$ wave in leads V5 and V7, and the infrequent occurrence of atrial fibrillation are important electrocardiographic points in differentiating patients with constrictive cardiomyopathy from those with constrictive pericarditis.

Of our 9 patients with constrictive cardiomyopathy, 4 have come to necropsy. Of these, 3 showed severe degrees of right ventricular involvement (muscular hypertrophy in 2 and extensive amyloid deposition in 1): the findings in the fourth are not known. This high incidence of significant pathological involvement of the right ventricle is of special interest in view of the frequency of right ventricular hypertrophy on the electrocardiogram.

The differential diagnosis of constrictive cardiomyopathy from constrictive pericarditis may present considerable clinical difficulty. As has been shown, a prolonged QTc, sinus rhythm, right rather than left atrial hypertrophy, and unimpressive $T$ wave changes favour the diagnosis of cardiomyopathy, whereas atrial fibrillation, sinus rhythm with left atrial enlargement, and extensive $T$ wave changes favour pericarditis. There was a greater tendency in cardiomyopathy than in pericarditis to a dominant $\mathrm{S}$ wave in V5, presumably as a result of the right ventricular hypertrophy found in cardiomyopathy. The greater incidence of $T$ wave inversion in left præcordial leads in pericarditis presumably reflects the pericardial disorder. The long QTc in cardiomyopathy must be presumed to be due to the generalized muscle disorder which is not commonly present in pericarditis.

\section{SUMMARY}

The electrocardiograms of 28 patients with obstructive cardiomyopathy, 25 with congestive cardiomyopathy, and 9 with constrictive cardiomyopathy have been studied and the findings compared with those of 18 patients with aortic valvular stenosis, 16 with ischæmic heart disease, and 10 with constrictive pericarditis, respectively.

No one specific electrocardiographic feature was noted either among the three types of cardiomyopathy studied or between them and the disease they resemble clinically.

Among the three types of cardiomyopathy studied a tall $R$ in leads I, V3, and V5, biventricular 
hypertrophy, and considerable QTc prolongation suggested the diagnosis of obstructive cardiomyopathy. Similarly a small $\mathrm{r}$ in leads V3 and V5, normal ventricular balance, prolonged QTc, atrial fibrillation, and heart block, suggested congestive cardiomyopathy. Generally low voltage, normal ventricular balance, or right ventricular hypertrophy with normal or slight QTc prolongation suggested constrictive cardiomyopathy.

A tall R in V3, a right atrial P wave, combined ventricular hypertrophy, and absence of heart block favoured a diagnosis of obstructive cardiomyopathy rather than aortic stenosis. Normal ventricular balance, heart block, and atrial fibrillation favoured congestive cardiomyopathy rather than ischæmic heart disease. A normal $\mathbf{P}$ wave axis, a prolonged QTc, a normal sinus rhythm, $\mathrm{T}$ wave inversion in V4R with upright $\mathrm{T}$ waves in V1, V3, V5, and V7 favoured the diagnosis of constrictive cardiomyopathy rather than constrictive pericarditis.

The implications of these findings are discussed.

\section{ADDENDUM}

Since this paper was written, one patient with obstructive cardiomyopathy with virtually complete left bundle-branch block has been seen.

\section{REFERENCES}

Abdin, Z. H. (1958). The electrocardiogram in aortic stenosis. Brit. Heart J., $20,31$.

Ashman, R., Byer, E., and Bayley, R. H. (1943). The normal human ventricular gradient I. Factors which affect its direction and its relation to the mean QRS axis. Amer. Heart J., 25, 16.

$\longrightarrow$, and Hull, E. (1941). Essentials of Electrocardiography, 2nd ed. Macmillan, New York.

Bercu, B. A., Diettert, G. A., Danforth, W. H., Pund, E. E., Jr., Ahlvin, R. C., and Belliveau, R. R. (1958). Pseudoaortic stenosis produced by ventricular hypertrophy. Amer. J. Med., 25, 184.

Björk, V. O., Jonsson, B., and Nordenström, B. (1958). Subaortic stenosis. Thorax, 13, 201.

Brent, L. B., Aburano, A., Fisher, D. L., Moran, T. J., Myers, J. D., and Taylor, W. J. (1960). Familial muscular subaortic stenosis. Circulation, 21, 167.

Brock, R. (1959). Functional obstruction of the left ventricle. Guy's Hosp. Rep., 108, 126.

Carter, E. P., Richter, C. P., and Greene, C. H. (1919). A graphic application of the principle of the equilateral triangle for determining the direction of the electrical axis of the heart in the human electrocardiogram. Bull. Johns Hopk. Hosp., 30, 162.

Goodwin, J. F., and Abdin, Z. H. (1959). The cardiogram of congenital and acquired right ventricular hypertrophy. Brit. Heart J., 21, 523.

-, Gordon, H., Hollman, A., and Bishop, M. B. (1961). Clinical aspects of cardiomyopathy. Brit. med. $J ., 1,69$.

- , Hollman, A., Cleland, W. P., and Teare, D. (1960). Obstructive cardiomyopathy simulating aortic stenosis. Brit. Heart J., 22, 403.

Hollman, A., Goodwin, J. F., Teare, D., and Renwick, J. W. (1960). A family with obstructive cardiomyopathy (asymmetrical hypertrophy). Brit. Heart J., 22, 449.

Kissin, M., Schwarzschild, M. M., and Bakst, H. (1948). A nomogram for rate correction of the Q-T interval in the electrocardiogram. Amer. Heart J., 35, 990.

Leatham, A. (1950). The chest lead electrocardiogram in health. Brit. Heart J., 12, 213.

Menges, H., Brandenburg, R. O., and Brown, A. L. (1961). Clinical, hemodynamic, and pathologic diagnosis of muscular subvalvular aortic stenosis. Circulation, 24, 1126.

Mitchell, A. M., Sackett, C. H., Hunzicker, W. J., and Levine, S. A. (1954). The clinical features of aortic stenosis. Amer. Heart J., 48, 648 .

Morrow, A. G., and Braunwald, E. (1959). Functional aortic stenosis: a malformation characterized by resistance to left ventricular outflow without anatomic obstruction. Circulation, 20, 181.

Myers, G. B. (1950). The form of the QRS complex in the normal precordial electrocardiogram and in ventricular hypertrophy. Amer. Heart J., 39, 637.

-, Klein, H. A., and Stofer, B. E. (1948). The electrocardiographic diagnosis of right ventricular hypertrophy. Amer. Heart J., 35, 1.

Pagnoni, A., and Goodwin, J. F. (1952). The cardiographic diagnosis of combined ventricular hypertrophy. Brit. Heart J., 14, 451.

Sodi-Pallares, D., and Calder, R. M. (1956). New Bases of Electrocardiography. Kimpton, London.

Sokolow, M., and Lyon, T. P. (1949a). The ventricular complex in left ventricular hypertrophy as obtained by unipolar precordial and limb leads. Amer. Heart J., 37, 161.

- , (1949b). The ventricular complex in right ventricular hypertrophy as obtained by unipolar precordial and limb leads. Amer. Heart J., 38, 273.

Teare, D. (1958). Asymmetrical hypertrophy of the heart in young adults. Brit. Heart J., 20, 1. 